\title{
Understanding Relation of Website Functionality with Behavioural Intention in Online Shopping Context
}

\author{
Ms Urvashi Gupta; *Professor Ravi Kiran (Corresponding Author) \\ Teaching Assistant; Professor In-charge Alumni Relations and Former Head, \\ School of Humanities and Social Sciences, Thapar University, Patiala
}

\begin{abstract}
The current research was undertaken to understand the key factors of website functionality influencing customer satisfaction towards online retailing in India. Data was collected from 365 respondents of North Indian states. The findings of the study reveal that security and privacy, website design and navigation are significant dimensions of website functionality and website functionality is significantly related to behavioural intention. This research will help online retailers in convincing new customers to take advantage of online retailing and existing customers to increase their usage of online shopping in developing nations like India. This study will help online retailers to improve negative shopping experiences, improve post purchase satisfaction and eventually increase customers of online shopping.
\end{abstract}

Key words: online retailing, website functionality, website design, customer satisfaction

\section{Introduction}

The Indian e-Commerce industry has shown remarkable growth since 2007 and a lot of enthusiasm is prevailing for its future growth. The Indian e-commerce in its long 10 year journey has advanced from a purely online travel-driven business to one which has many different categories and niche segments. In the current decade, online retailing has entered our day to day life through products and services namely financial services, apparels, personal care products, gadgets and many others.

The reliance on online retailing can be estimated through the facts that its size in Indian market had been estimated as $14 \mathrm{Bn}$ USD in 2012 and is projected to reach 74 Bn USD by 2017 (Singh et al., 2012). Though online retailing is still a very small part of overall retail in India $(0.1 \%)$, it is projected to grow at a fast pace (reaching approximately $2 \%$ by 2017) and over the next decade its presence will be even more momentous.

Various factors that have contributed towards an increase in online buying in Indian cities include growing aspirations, changing lifestyles and increasing purchasing power of people. Another driver for growth is multiple payment options offered by players (like Cash on delivery) and the flexibility in product replacements/exchanges, which have instilled confidence in the small town consumers and created trust in online buying. Since there are limited studies conducted in India, therefore the literature reliance has been on most of the studies conducted in developed countries of world which switched to online retailing earlier than India. But the models prevalent in developed countries cannot be generalised for developing countries like India which have different socio-cultural background. Therefore, the objective of this study is to identify and analyse features of website that lead to behavioural intention.

The findings of our study are useful for online retailers in various ways. Based on our findings they can understand important website features which will make their websites more user friendly and in turn infuse confidence among consumers about online shopping. Our model will help online retailers to improve negative shopping experiences, improve post purchase satisfaction and eventually increase customers of online shopping. This study has a higher relevance in developing countries where switch over to internet had been of much after their active adoption in Western countries. 


\section{Theoretical Background}

\section{1 Behavioural intention}

Behavioural intention has received much attention in the past few years and is widely used in the models of technology acceptance. Behavioural intention is defined as a person's intention to perform various behaviours (Ajzen, 1991).

\subsection{Website functionality and behavioural intention}

The quality of a website can be accessed through website functionality. A website can be evaluated on the basis of performance of certain functions such as atmospherics of website (Prasad and Ansari, 2009; Ha and Stoel, 2009) ease to use features of website (Khare and Rakesh, 2011; Dholakia and Zhao, 2010) and usability (Hernandez et al., 2009; Chen et al., 2010). Scholars have developed attributes to envisage security features of website (Mukherjee and Nath 2007; Nair 2009; Maditinos and Theodoridis 2010; Gehrt et al., 2012; Sharma and Lijuan, 2014), website service quality (Wolfinbarger and Gilly 2003; Bansal et al., 2004; Nair and Prabhakar 2007; Lin and Sun, 2009; Shin et al., 2013), website service quality (Wolfinbarger and Gilly, 2003; Nair and Prabhakar, 2007; Lin and Sun, 2009), navigability (Nair, 2009; Lee and Kozar, 2012), and coordinating products on website (Chen et al., 2010) which lead to behavioural intention. Lee and Kozar (2012) found that social networking features including facebook, youtube and twitter becoming pervasive; e-business sites have rushed to integrate these social networking features into their websites, enabling enhanced interactive communications between consumers or between consumers and companies. A study by Singh et al., (2006) predicted that websites that adapt to Indian culture were shown to be perceived more favourably. While a number of attributes` have been identified and efforts have been made to show that these are related to satisfaction but little commonality exists among the scales developed for measuring website characteristics important for the customers.

Therefore, website features are important for customer satisfaction and need to be taken into greater depth.

Therefore, the hypotheses proposed are as under:

H1: Website functionality is a multidimensional construct significantly predicted by security and privacy, website design, navigation characteristics, atmospheric features and consistency features.

\section{H2: There is a significant positive association between website functionality and behavioural intention.}

Although enough work has been done on these; still it is attracting researchers from all over the world and new dimensions are being added. The models applicable in developed countries need to be introspected in-depth to find out their applicability in developing countries like India. The present study is an attempt in this direction to find out the important predictors of customer satisfaction in online retailing.

\section{Research Methodology}

\subsection{Survey Instrument}

The present study is based upon primary data. After literature review, a self-administered questionnaire was developed to capture the data from the users of online shopping. Where-ever possible initial scale items were taken from previously validated measures in online purchase satisfaction and then reorganised and adapted to current content. Prominent website functionality items reported by Prasad and Ansari, 2009; Ha and Stoel, 2009; Dholakia and Zhao, 2010; Chen et al., 2010; Maditinos and Theodoridis, 2010; Wolfinbarger and Gilly, 2003; Lin and Sun, 2009 were included in this study.

\subsection{Data Collection Procedures}

In order to get accurate responses and reduce ambiguity, a preliminary questionnaire was distributed to a pilot group of 50 people selected on the basis of convenience sampling. The pilot group not only answered the questions but also suggested some changes in the wording and relevance of questions. The final questionnaire had close-ended questions on a 5-point Likert scale. A total of 2000 questionnaires were administered to service class people, businessmen and youth including students. A total of 465 responses were obtained. Of these, 365 usable questionnaires were retained. 


\section{Results and Analysis}

\subsection{Demographic Profile of Respondents}

TABLE I: Frequency Distribution for respondent's demographics

\begin{tabular}{|c|c|c|c|}
\hline Demographic Characteristics & $\mathrm{N}=365$ & Response & $\begin{array}{c}\text { Valid } \\
\text { percentage } \\
\end{array}$ \\
\hline \multicolumn{4}{|l|}{ Gender } \\
\hline Male & & 201 & 55.06 \\
\hline Female & & 164 & 44.94 \\
\hline \multicolumn{4}{|l|}{ Age } \\
\hline $18-30$ & & 248 & 67.9 \\
\hline $31-45$ & & 83 & 22.7 \\
\hline Above 45 & & 34 & 9.3 \\
\hline \multicolumn{4}{|l|}{ Education Qualification } \\
\hline Undergraduate & & 100 & 27.4 \\
\hline Graduate & & 89 & 24.4 \\
\hline Post graduate & & 176 & 48.2 \\
\hline \multicolumn{4}{|l|}{ Nature of consumer } \\
\hline Student & & 158 & 43.3 \\
\hline Self-employed & & 42 & 11.5 \\
\hline Service & & 165 & 45.2 \\
\hline \multicolumn{4}{|l|}{ Annual income } \\
\hline Less than 3.5 lakhs & & 231 & 63.3 \\
\hline 3.5-6 lakhs & & 90 & 24.7 \\
\hline More than 6 lakhs & & 44 & 12.0 \\
\hline \multicolumn{4}{|c|}{ Number of hours spent on internet in a week } \\
\hline Less than 7 hours & & 110 & 30.1 \\
\hline $8-16$ hours & & 126 & 34.5 \\
\hline More than 16 hours & & 129 & 35.3 \\
\hline \multicolumn{4}{|c|}{ Number of years of online shopping } \\
\hline Less than 1 year & & 145 & 39.7 \\
\hline $1-3$ years & & 169 & 46.3 \\
\hline More than 3 years & & 51 & 14.0 \\
\hline \multicolumn{4}{|c|}{ Hours spend on online shopping in a month } \\
\hline Less than 2 hours & & 152 & 41.6 \\
\hline 2-6 hours & & 168 & 46.0 \\
\hline More than 6 hours & & 45 & 12.4 \\
\hline \multicolumn{4}{|c|}{ Number of products purchased online in a month } \\
\hline Less than 2 & & 73 & 20.0 \\
\hline $2-5$ & & 152 & 41.6 \\
\hline More than 5 & & 140 & 30.4 \\
\hline
\end{tabular}

\subsubsection{Demographic Profile}

The above table shows the basic characteristics of the consumers surveyed. It appears that significant number of respondents were well educated i.e., postgraduates and graduates, of young age and enjoying average income. 


\subsubsection{Reliability and Validity}

To assess measurement model reliability and validity of the proposed measurement model, confirmatory factor analysis (CFA) was carried out on all the constructs. Based on the analysis, ten items of website functionality out of fifteen and five items of behavioural intention were retained for further analysis. While navigation (3), website design (3) and security and privacy(4) were retained for further analysis but atmospheric features (3) and consistency feature of website(2) was completely removed due to unclear factor structure and poor loadings. The instrument demonstrates evidence of convergent validity (average variance extracted $>0.50$ in all occasions), composite reliability (values $>0.70$ in all occasions) and discriminant validity (AVE estimate of each construct is larger than the squared correlations of this construct to any other construct (Fornell and Larcker, 1981).

\subsection{Measurement Model}

\subsubsection{Website functionality}

Website functionality was conceptualised as second order independent variable in the model. Based on first order CFA, three items of navigation, three items of website design and four items of security and privacy were retained. These three constructs measured with ten items were converged into second order construct website functionality. The model fit indices $(\mathrm{CMIN} / \mathrm{df}=2.372, \mathrm{GFI}=0.95, \mathrm{CFI}=0.93$, TLI=0.91, RMSEA=0.06) indicate an acceptable level of model fit. These results partially support $\mathrm{H} 1$ that Website functionality is a second order multidimensional construct explained through navigation, website design and security and privacy.

TABLE II: The measurement model

\begin{tabular}{|llccccc|}
\hline & Items & $\begin{array}{c}\text { Standardised } \\
\text { loadings }\end{array}$ & SE & CR & $\begin{array}{c}\text { Composite } \\
\text { Reliability }\end{array}$ & AVE \\
\hline Website Design & WD4 & 0.52 & 1 & & & \\
& WD3 & 0.81 & 0.185 & 8.359 & 0.82 & 0.65 \\
& WD2 & 0.74 & 0.186 & 8.392 & & \\
\hline Navigation & NAV1 & 0.66 & 0.095 & 9.373 & & \\
& NAV2 & 0.65 & 0.114 & 8.291 & 0.8 & 0.59 \\
& NAV3 & 0.71 & 1 & & & \\
\hline Security and Privacy & SP1 & 0.62 & 0.132 & 8.331 & & \\
& SP2 & 0.8 & 0.177 & 9.402 & 0.87 & \\
& SP3 & 0.81 & 0.17 & 9.385 & & \\
& SP4 & 0.63 & 1 & & & \\
\hline Behavioural intention & BI1 & 0.71 & 0.032 & 15.393 & & \\
& BI2 & 0.67 & 0.029 & 13.942 & & \\
& BI3 & 0.72 & 0.033 & 16.052 & 0.95 & \\
& BI4 & 0.65 & 0.028 & 14.103 & & \\
& BI5 & 0.84 & 1 & & & \\
\hline
\end{tabular}

\subsubsection{Second-order $\mathrm{CFA}$}

Based on the relationships proposed and subsequent analysis depicted in table II all the first order independent variables namely navigation, website design and security and privacy load on the second order independent variable website functionality. Next the hypothesised second order model was estimated using AMOS20.0 separately. The AMOS output of second order CFA of website functionality, perceived usability, perceived usefulness and customer satisfaction $(\mathrm{CMIN} / \mathrm{df}=3.047, \mathrm{GFI}=0.941, \mathrm{CFI}=0.928$, TLI=0.901, RMSEA=0.07), indicated an acceptable fit with the data. The measurement model has been found to qualify goodness of fit indices as various fit indices are within the prescribed limits. Since, the second order solution did 
not result in a significant decrease in model fit, it can be concluded that the proposed second-order model provided a good account for correlations among first order constructs.

TABLE IV: Second Order Measurement Model

\begin{tabular}{lllccc}
\hline First order & Path & Second order & $\begin{array}{l}\text { Standardised } \\
\text { estimate }\end{array}$ & S.E & C.R \\
\hline Website design & $<--$ & Website functionality & 0.521 & 0.096 & 9.076 \\
Navigation & $<--$ & Website functionality & 0.732 & & \\
Security and privacy & $<---$ & Website functionality & 0.49 & 0.111 & 8.526 \\
\hline
\end{tabular}

\subsection{Path analysis}

The next step involved was testing of the structural model and corresponding theoretical relationships. The path relationships within the research model were analysed by structural equation modelling (SEM) using AMOS 20. The overall fit indices of the research model are shown acceptable $(\mathrm{CMIN} / \mathrm{df}=3.111$, GFI $=0.938$, $\mathrm{CFI}=0.923$, TLI=0.90, RMSEA=0.07). This indicates that the hypothesized model is the reasonable presentation of the structures underlying the observed data.

\begin{tabular}{ccccccc}
\hline Hypothesis & $\begin{array}{c}\text { Independent } \\
\text { variable }\end{array}$ & Path & $\begin{array}{c}\text { Dependent } \\
\text { variable }\end{array}$ & $\begin{array}{c}\text { Path } \\
\text { coefficient }\end{array}$ & p & Result \\
\hline $\mathrm{H}_{2}$ & $\begin{array}{c}\text { Website } \\
\text { Functionality }\end{array}$ & $\rightarrow$ & $\begin{array}{c}\text { Behavioural } \\
\text { Intention }\end{array}$ & 0.456 & $* * *$ & Supported*** \\
\hline
\end{tabular}

Notes: *** $\mathbf{p}<0.001$

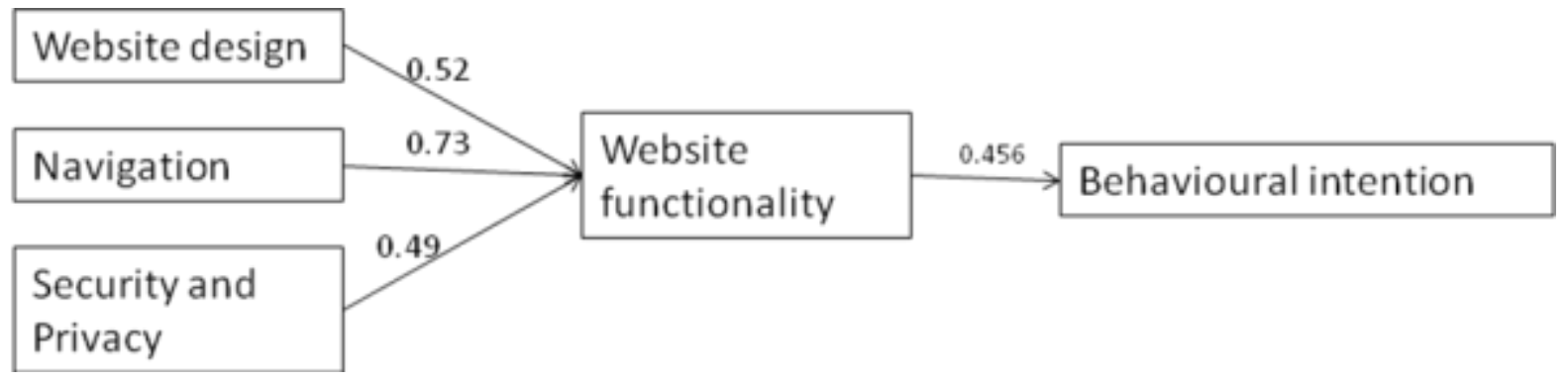

Figure: Research Model

\section{Discussion and Conclusion}

In the following section, results of the study are discussed. The research contributes to an overall understanding of website functionality and its relationship with behavioural intention in Indian context. The study also reports the limitations of the study and suggests topics for further research.

The first objective of the study has been to identify those features of websites which have an impact on behavioural intention. Measurement model analysis indicated that navigation characteristics of websites followed by website design and security and privacy are the significant dimensions of website functionality. Researchers have also observed positive evaluation of security and privacy and website design in USA (Ha and Stoel, 2009; Lee and Kozar, 2012; Dholakia and Zhao, 2010), Greece (Maditinos and Theodoridis 2010), Spain (Hernandez et al., 2009), China (Lin and Sun, 2009; Chen et al., 2010; Guo et al., 2012; Sharma and Lijuan, 2014) and India (Nair, 2009; Prasad and Ansari, 2009; Gehrt et al., 2012). This indicates security and privacy protection is an important driver influencing online purchase. The concern of security and privacy is a vital issue demanding attention of online retailers. Navigation also emerged as one of the important factors for online transactions. This supports the earlier studies by Palmar (2002) and Calisir et al., (2009) who insisted that navigation is important for the success of a website. This indicates that consumers incline to find the pertinent 
information with least efforts through graphical components, hyperlinks and layouts of websites. Additionally, feedback mechanism also helps in information retrieval. There is a comprehensive improvement in online security technologies over the years as online shopping is being adapted by people. Almost every online retailer's website has detailed privacy statement meant at stimulating customer confidence. Consumers may be concerned about possible theft, product performance therefore online retailers must provide best online security as it is the vital prerequisite. As reflected through the present study, inadequately designed web pages, outdated information, tedious navigation procedures, intricate language and complicated check-out procedures all contribute to abandonment of shopping cart by consumers. Online retailers should keep the home page simple with easily readable fonts and universally understood symbols. The contents need to be spread evenly across web pages. Moreover, online retailers need to work upon the interactive display of information on their websites leading to final purchase.

One such initiative taken by online retailer flipcart.com in 2010 is cash-of-delivery (COD) mode of payment. This has reduced the fear of giving information through debit card and credit card and has instilled confidence in Indian shoppers to adopt online shopping. COD has also been found significant in the present study.

\subsection{Limitations and Future Research}

As is true for many studies, present study was conducted for respondents from North India. Although to remove this geographical limitation an effort was made to compare results with those of studies conducted in south and west as well. The study also validates the significance of cash-on-delivery mode of payment for the first time. Cash-on-delivery mode of payment needs to be validated further in the models of developing countries. Since we conducted the research in North India only, future studies may include rural and semi-urban areas also having limited access to technology adoption.

\section{Appendix I}

Scale Items

Website functionality: (Prasad and Ansari, 2009; Ha and Stoel, 2009; Dholakia and Zhao, 2010; Chen et al., 2010; Maditinos and Theodoridis, 2010; Wolfinbarger and Gilly, 2003; Lin and Sun, 2009)

Website design

Website functionality Navigation

Security and privacy

Behavioural intention
The attractive colour scheme of online retailing websites facilitates shopping. WD2

The graphics displayed in websites provide ease for ordering product. WD3 Shopping online is an exciting experience. WD4

Pictures of products are downloaded quickly. NAV1

The search function at the websites is helpful. NAV2

The websites allow easy return to the previous display pages. NAV3

The websites have adequate security measures. SP1

I feel safe while using my credit card/ debit card on the websites.SP2

I trust that the websites will not give my personal details to other websites

without my permission. SP3

I am satisfied with product range offered by online retailers. BI1

I am satisfied with the quality of products offered online. BI2

I would continue to purchase products online. BI3

I recommend online shopping websites to other people.BI4

**Online shopping is a satisfying experience as it offers cash-on-delivery

mode of payment. BI5

** New scale item.

\section{References}

[1] Ajzen, "The Theory of Planned Behavior", Organizational Behavior and Human Decision Processes, vol. 50, pp. 179-211, 1991.

http://dx.doi.org/10.1016/0749-5978(91)90020-T 
[2] H.S. Bansal, G.H.G. Mc Dougall, S.S. Dikolli, and K.L. Sedatole, "Relating e-satisfaction to behavioural outcomes; an empirical study", Journal of Services Marketing, vol. 18, pp. 290-302, (2004).

http://dx.doi.org/10.1108/08876040410542281

[3] F. Calisir, E.A. Bayraktarog lu, C.A. Gumussoy, Y.I. Topcu and T. Mutlu, "The relative importance of usability and functionality factors for online auction and shopping websites", Online Information Review, vol. 34, pp. 420-439, 2010. http://dx.doi.org/10.1108/14684521011037025

[4] R.R. Dholakia, and M. Zhao, "Effects of online store attributes on customer satisfaction and repurchase intentions", International Journal of Retail and Distribution Management, vol. 38, 482-496, 2010. http://dx.doi.org/10.1108/09590551011052098

[5] C.K. Gehrt, N.M. Rajan, G. Shainesh, D. Czerwinski, and M. O’Brien, "Emergence of online shopping in India: shopping orientation segments", International Journal of Retail and Distribution Management, vol. 40, pp. 742-758, 2012. http://dx.doi.org/10.1108/09590551211263164

[6] X. Guo, K.C. Ling and M. Liu, "Evaluating factors influencing customer satisfaction towards online shopping in China", Asian Social Science, vol. 8, pp. 40-50, 2012. http://dx.doi.org/10.5539/ass.v8n13p40

[7] S. Ha and L. Stoel, "Consumer e-shopping, acceptance: antecedents in a technology acceptance model", Journal of Business Research, vol. 62, pp. 565-571, 2009. http://dx.doi.org/10.1016/j.jbusres.2008.06.016

[8] B. Hernandez, J. Jimenez and J.M. Martin, "The impact of self-efficacy, ease of use and usefulness on e-purchasing: an analysis of experienced e-shoppers", Interacting with Computers, vol. 21, pp. 146-156, 2009. http://dx.doi.org/10.1016/j.intcom.2008.11.001

[9] Internet in urban India, IAMAI report, September, 2012 available at http://www.iamai.in/reports1.aspx ( accessed on November 2012).

[10] K.G. Jo“reskog, D. Sorbom and K.G. Jhoreskog. LISREL 7 User's Reference Guide. Scientific Software, Mooresville, IN. 1989.

[11] A. Khare, and S. Rakesh, "Antecedents of online shopping behaviour in India: an examination", Journal of Internet Commerce, vol. 10, pp. 227-244, 2011. http://dx.doi.org/10.1080/15332861.2011.622691

[12] T.R.G. Lin and C.C. Sun, "Factors influencing satisfaction and loyalty in online shopping: an integrated model", Online Information Review, vol. 33, pp. 458-475, 2009. http://dx.doi.org/10.1108/14684520910969907

[13] I.D. Maditinos and K. Theodoridis, "Satisfaction determinants in Greek online shopping context", Information Technology and People, vol. 23, pp. 312-329, 2010. http://dx.doi.org/10.1108/09593841011087789

[14] A. Mukherjee and P. Nath, "Role of electronic trust in online retailing: a re-examination of the commitment-trust theory" European Journal of Marketing, vol. 41, pp. 1173-1202, 2007. http://dx.doi.org/10.1108/03090560710773390

[15] J.R. Nair, "E-Tailing paradigm: a diagnostic and prognostic study of e-tailing practices in Bangalore metropolitan area", Dharana: Bhavan's International Journal of Business, vol. 3, 32-59, 2009.

[16] J.W. Palmar, "Website usability, design and performance metrics", Information System Research, vol. 13, pp. 151$167,2002$. http://dx.doi.org/10.1287/isre.13.2.151.88

[17] J.S. Prasad and A.R. Aryasri, "Determinants of shopper behaviour in e-tailing: an empirical analysis", Paradigm, vol.13, pp. 73-83, 2009. http://dx.doi.org/10.1177/0971890720090110

[18] G. Sharma and W. Lijuan, "Ethical perspectives on e-commerce: an empirical investigation", Internet Research, vol. 24, pp. 414-435, 2014. http://dx.doi.org/10.1108/IntR-07-2013-0162

[19] J.I. Shin, K.H. Chung, J.S. Oh and C.W. Lee "The effect of site quality on repurchase intention in internet shopping through mediating variables; the case of University students in South Korea" International Journal of Information Management, vol. 33, pp. 453-463, 2013. http://dx.doi.org/10.1016/j.ijinfomgt.2013.02.003

[20] P. Singh, A. Anand and A. Modi, "E-tailing in India-pushing the retail frontier", August 2012, pp. 3-13, available at http://www.technopak.com/resources/retail/E-tailing\%20Report\%202012.pdf. (accessed 20 November 2012)

[21] S.S. Singh, N. Dalal, and N. Spears, "Understanding web home page perception" European Journal of Information Systems, vol. 14, pp. 288-302, 2005. 
http://dx.doi.org/10.1057/palgrave.ejis.3000525

[22] M. Wolfinbarger and C.M. Gilly "eTailQ: dimensionalising, measuring and predicting e-tail quality" Journal of Retailing, vol. 79, pp. 183-198, 2003. http://dx.doi.org/10.1016/S0022-4359(03)00034-4

[23] Y.Lee and K.A. Kozar, "Understanding of website usability: Specifying and measuring constructs and their relationships", Decision Support Systems, vol.52, 450-463, 2012.

http://dx.doi.org/10.1016/j.dss.2011.10.004 